\title{
Radiographic Localization of Mental Foramen in Northeast and South Indian Ethnic Groups of Indian Population
}

\author{
${ }^{1}$ Vinod Kumar, ${ }^{2}$ Prahalad Hunsigi, ${ }^{3}$ Balakasi Reddy Kaipa, ${ }^{4}$ Rajini Reddy, ${ }^{5}$ Kranti Kiran Reddy Ealla \\ ${ }^{6}$ Chakki B Arun Kumar, ${ }^{7}$ MD Prasanna
}

\begin{abstract}
Background and objectives: The position of mental foramen varies in different ethnic groups. The position of mental foramen is mainly important for achieving effective mental nerve block to carry out dental surgical procedures in mandible. Deviation in its position can be a cause of complication during local anesthesia or surgical procedures. The position of the mental foramen in South Indian and Northeast Indian population has not been reported.

The purpose of the current study was to determine the most common location of the mental foramen (MF) and its bilateral symmetry in selected Indian population.
\end{abstract}

Materials and methods: 380 digital panoramic radiographs (DPR) of a randomly selected 2 Ethnic groups of Indian population were studied.

Results: The common position (59.2\%) of the mental foramen was located between the 1st and 2nd premolars (P3) in Northeast Indians and in South Indians the common location $(62.8 \%)$ was in line with the long axis of the 2 nd premolar (P4), which was statistically significant in both Populations.

Conclusion: A bilateral symmetry was observed in the location of mental foramina, either mesial to or in line with the long axis of the 2nd premolar, which is consistent with the observations of similar studies in various ethnic or racial groups. In our study a statistically significant association between the 2 ethnic groups and the position of mental foramen exists. Therefore the position of mental foramen may be specific to racial groups facilitating accurate landmark for mental nerve

\footnotetext{
${ }^{1,4,5}$ Reader, ${ }^{2,6,7}$ Professor and Head, ${ }^{3}$ Senior Lecturer

${ }^{1}$ Department of Pedodontics, Navodaya Dental College and Hospital, Raichur, Karnataka, India

2Department of Oral and Maxillofacial Pathology, AME's Dental College and Research Centre, Raichur, Karnataka, India

${ }^{3,4}$ Department of Conservative Dentistry and Endodontics, MNR Dental College and Hospital, Sangareddy, Telangana, India

${ }^{5,7}$ Department of Oral Pathology and Microbiology, MNR Dental College and Hospital, Sangareddy, Telangana, India

${ }^{6}$ Department of Oral and Maxillofacial Pathology, Guru Govind Singh College of Dental Sciences and Research Centre Burhanpur, Madhya Pradesh, India
}

Corresponding Author: Kranti Kiran Reddy Ealla, Reader Department of Oral Pathology and Microbiology, MNR Dental College and Hospital, Sangareddy, Telangana, India, Phone: 91-9849409070, e-mail: drekkr@yahoo.co.in block depending on the ethnic group. Further, studies are required with larger sample for better understanding of mental foramen location in different ethnic groups.

Keyword: Mental foramen, Mental nerve block, Mental nerve.

How to cite this article: Kumar V, Hunsigi P, Kaipa BR, Reddy $\mathrm{R}$, Ealla KKR, Kumar CBA, Prasanna MD. Radiographic Localization of Mental Foramen in Northeast and South Indian Ethnic Groups of Indian Population. J Contemp Dent Pract 2014;15(6):766-769.

\section{Source of support: Nil}

Conflict of interest: None declared

\section{INTRODUCTION}

Mid-way between the upper and lower borders of mandible harbors an opening called the mental foramen on either side. ${ }^{1}$ The mental foramina are found close to the apices of premolars on the buccal cortical plate, directed superiorly and posteriorly when seen from inside out. They are consistently observed at the same level, i.e. 13 to $15 \mathrm{~mm}$ above the lower border of the mandible. Each mental foramen carries the mental nerve and vessels. ${ }^{2}$ The mental nerve is one of the terminal branches of inferior alveolar nerve, supplying sensory fibers to the lower lip, the gingiva and the buccal vestibule anterior to the lower first molar. ${ }^{3}$

Trauma to the mental nerve during surgical manipulation may result in paresthesia or anesthesia of the corresponding areas. The accurate localization of the mental foramen, followed by local anesthetic delivery is essential to achieve anesthesia of the incisive branches of the inferior alveolar nerve and the mental nerve. Hence, the knowledge on exact location and orientation of the mental canal and the foramen are very important in clinical dentistry, such as the administration of local anesthesia for surgical, operative or diagnostic purposes and in endodontic treatment. Anatomically, there is one mental foramen on each side of the mandible through which passes the mental artery and vein and the mental nerves, the larger of the two terminal branches of the inferior alveolar nerve. ${ }^{3,4-8}$

Data from various ethnic groups like Tanzanian, Thai, Chinese, Saudi Arabia, Malaysian, Mongoloid, Caucasian's show variations in the location of the mental 
foramen. ${ }^{9}$ Mental foramen location may be specific to racial groups facilitating accurate land mark for mental nerve block depending on the ethnic group. Since, there is almost no data available about the comparison of the position of mental foramen in South Indian and Northeast Indian ethnic groups, the present study was carried out to determine the position of mental foramen in two different populations namely, South Indian and Northeast Indian populations.

\section{MATERIALS AND METHODS}

The study consisted of 380 subjects belonging to 2 groups of geographically different regions and different ethnicity of India, namely South Indians and Northeast Indian students studying at various professional colleges in and around Raichur city. Informed consent was obtained from the patient prior to the commencement of the study. Ethical clearance was obtained from the institutional ethical committee board.

\section{Criteria for Selecting the Population}

1. Northeast Indian population: Subjects belonging to Mongoloid race showing Mongol features who are original inhabitants of Northeast part of India namely Assam, Arunachal Pradesh, Nagaland, Mizoram, Manipur, Meghalaya and Tripura.

2. South Indian population: Subjects belonging to AryanDravidian race showing Dravidian features who are original inhabitants of Southern States of India, namely Andhra Pradesh, Karnataka, Tamil Nadu and Kerala.

Panoramic radiographs were obtained from the subjects which were of dentate patients with erupted 1st and 2nd premolars and permanent 1st molars.

\section{Exclusion Criteria were as follows}

1. Presence of a radiolucent lesion in the lower jaw anywhere in the area extending from the right first molar to the left first molar.

2. Presence of a missing tooth in the lower jaw (between 36 and 46).

3. Nonvisualization of the mental foramen bilaterally.

4. Incomplete eruption of permanent teeth.

5. Patient below 18 years.

6. Presence of periodontal lesions.

7. Patient with previous orthodontic treatment.

8. Presence of crowding and spacing in the lower arch.

9. Films with exposure or processing artifacts.

Two observers who had been calibrated by the principle investigator read the radiographs. The vertical line, which is imaginary long axis of the tooth, is drawn along the midfacial surface of tooth, if the vertical line crossed the mental foramen this position would be called aligned with these teeth. If the mental foramen was between two long axes of 2 teeth the position would be between the 2 teeth. The position of the image of the mental foramen in relation to the apices of teeth was recorded as follows: Position 1(P1): situated anterior the first premolar Position 2(P2): In line with the first premolar Position 3(P3): Between the first and second premolars Position 4(P4): In line with the second premolar Position 5(P5): Between the second premolar and first molar Position 6(P6): In line with the first molar.

\section{RESULTS}

Data was subjected to statistical analysis and expressed in term of proportion. Comparison between two populations was done by Chi-square test or Fisher's exact test for small sample. A p-value of less than 0.05 was considered as significant. Data was analyzed by software SPSS v16.0

Out of 380 subjects mental foramen was found to be symmetrical in 323 subjects (85\%) and 57 (15\%) subjects had asymmetrical mental foramen. The position of symmetrical mental foramen in South Indians and Northeast Indians are tabulated as follows:

In South Indian population $62.8 \%$ of mental foramen was at P4 (Fig. 1), 31.1\% of mental foramen was at P3, 3.7\% of mental foramen was at P5, $2.4 \%$ of mental foramen was at P2. In Northeast population 59.2\% of mental foramen was at P3, 36.9\% of mental foramen was at P4, 3.2\% of mental foramen was at P5 and 1.9\% of mental foramen was at P2 (Table 1).

Fifteen percent of subjects had asymmetrical mental foramen. On the left side (Table 2) the common positions of asymmetrical mental foramens in South Indians were at P4 (53.8\%) followed by P3 (38.5\%) and P5 (7.7\%). In

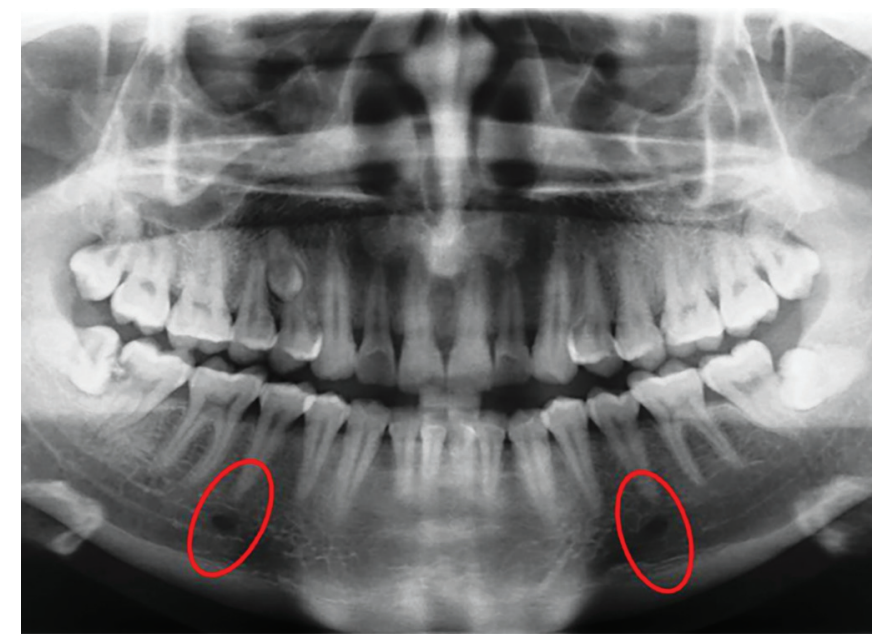

Fig. 1: Symmetrical mental foramen in line with long axis of 2nd premolar (Position 4) 
Northeast Indians the common positions of asymmetrical mental foramen were P4 (51.6\%), followed by P3 (41.9\%), and P5 (6.5\%) (Table 2).

On the right side, the common position of asymmetrical mental foramen in South Indians was P3 (46.2\%), followed by P4 (38.5\%), P5 (7.7\%), and P2 (7.7\%). In Northeast Indians the common positions of asymmetrical mental foramen was P3 (45.2\%), followed by P4 (41.9\%), P5 (6.5\%) and P2 (6.5\%) (Table 3).

\section{DISCUSSION}

The position of the mental foramen assumes greater importance for dental surgeons. The accurate anatomical location of mental foramen is very important while administering mental nerve block local anesthesia to avoid injury to neurovascular bundle. In 380 orthopantamograms, mental foramen location was found anywhere between the long axis of 1st premolar to that of the mesiobuccal root of 1 st molar. In majority of the cases (85\%) there was bilateral symmetry of the position.

In the present study panoramic radiograph was used because of certain advantages over intraoral radiographs. It includes greater area of soft and hard tissues and also the visualized area in continuity, thus allowing for more accurate localization of the mental foramen in both the horizontal and vertical dimensions. On the contrary periapical radiography may not reveal the position of the mental foramen if it is below the edge of the film. ${ }^{10,11}$

The location of the mental foramen could change during the development of the jaws ${ }^{12}$ therefore; panoramic radiographs taken from patients who had completed their development (above 18 years age) were evaluated in this study. In the present study, $85 \%$ of the mental foramen position is symmetrical. In south Indians the most common position observed was P4 (62.8\%) followed by P3 (31.1\%), P5 (3.7\%) and P2 (2.4\%). The same position was observed by Wang et $\mathrm{al}^{13}$ in Chinese population, Santini and Land ${ }^{14}$ Apinharmit et al, ${ }^{15}$ Gupta and Soni ${ }^{16}$ and shwetha Agnihotri et al. ${ }^{17}$

In Northeast Indians, the most common position observed was P3 with percentage of $59.2 \%$ followed by P4 with percentage $36.9 \%$, P5 with percentage 3.2\% and P2 with percentage 1.9\% which were in agreement with Olasoji et al. ${ }^{18}$

There was no case noted at position 1 (P1) and position 2 (P2). The present study was undertaken in order to evaluate the position of mental foramen in 2 different ethnic groups of Indian population and also to assess the predominant position if any in these 2 groups. Our findings are in agreement with the previous authors who also found variations in positions of mental foramen in various ethnic groups or races.

Table 1: Distribution of symmetrical mental foramen in relation to the apices of the teeth

\begin{tabular}{llllllll}
\hline Gender & Position 1 & Position 2 & Position 3 & Position 4 & Position 5 & Position 6 & Total \\
\hline South Indian & 0 & $4(2.4)$ & $51(31.1)$ & $103(62.8)$ & $6(3.7)$ & 0 & 164 \\
Northeast Indian & 0 & $3(1.9)$ & $93(59.2)$ & $58(36.9)$ & $5(3.2)$ & 0 & 159 \\
Total & 0 & 7 & 144 & 161 & 11 & 0 & 323 \\
p-value & $\mathrm{p}=0.99$ & $\mathrm{p}=0.99$ & $\mathrm{p}<0.0001$ & $\mathrm{p}<0.0001$ & $\mathrm{p}=0.99$ & $\mathrm{p}=0.99$ \\
Remarks & Not Significant & Not & Highly & Highly & Not significant & Not significant \\
& & significant & significant & significant & & \\
\hline
\end{tabular}

Table 2: Distribution of asymmetrical mental foramen in relation to the apices of the teeth (left side)

\begin{tabular}{llllllll}
\hline Gender & Position 1 & Position 2 & Position 3 & Position 4 & Position 5 & Position 6 & Total \\
\hline South Indian & 0 & 0 & $10(38.5)$ & $14(53.8)$ & $2(7.7)$ & 0 & 26 \\
Northeast Indian & 0 & 0 & $13(41.9)$ & $16(51.6)$ & $2(6.5)$ & 0 & 31 \\
Total & 0 & 0 & 23 & 30 & 4 & 0 & 57 \\
p-value & $\mathrm{p}=0.99$ & $\mathrm{p}=0.99$ & $\mathrm{p}=0.78$ & $\mathrm{p}=0.87$ & $\mathrm{p}=0.99$ & $\mathrm{p}=0.99$ \\
Remarks & Not significant & Not significant & Not significant & Not significant & Not significant & Not \\
& & & & & & significant \\
\hline
\end{tabular}

Table 3: Distribution of asymmetrical mental foramen in relation to the apices of the teeth (right side)

\begin{tabular}{llllllll}
\hline Gender & Position 1 & Position 2 & Position 3 & Position 4 & Position 5 & Position 6 & Total \\
\hline South Indian & 0 & $2(7.7)$ & $12(46.2)$ & $10(38.5)$ & $2(7.7)$ & 0 & 26 \\
Northeast Indian & 0 & $2(6.5)$ & $14(45.2)$ & $13(41.9)$ & $2(6.5)$ & 0 & 31 \\
Total & 0 & 4 & 26 & 23 & 4 & 0 & 57 \\
p-value & $\mathrm{p}=0.99$ & $\mathrm{p}=0.99$ & $\mathrm{p}=0.94$ & $\mathrm{p}=0.79$ & $\mathrm{p}=0.99$ & $\mathrm{p}=0.99$ & Not \\
Remarks & Not significant & Not significant & Not significant & Not significant & Not & significant & significant \\
& & & & & &
\end{tabular}


In the present study, on comparing the position of mental foramen in 2 different ethnic groups of Indian populations, the most common location of mental foramen among South Indian ethnic group (Aryan-Dravidian) was in line with the second premolar, whereas Northeast ethnic group (Mongoloid) showed significantly predominant location between the first and second premolars. On the whole, mental foramen location is distinctive to specific racial or ethnic group facilitating accurate land mark for mental nerve block depending on that particular ethnic group. Further studies should be carried out with different ethnic groups and with larger sample size for better understanding of the location of mental foramen.

\section{REFERENCES}

1. Chummy SS. Last's: Regional and applied. 11th ed. Churchill Livingstone Elsevier limited, 2006. p. 532.

2. Woelfel JB, Scheid RC. Structures that form the foundation for tooth function. Dental Anatomy: Its relevance to dentistry. 6th ed. Newyork: Lippincott, Williams and Wilkins: 2002. p. 19.

3. Moiseiwtsch JR. Position of the mental foramen in a North American, white population. Oral Surg Oral Med Oral Pathol Oral Radiol Endod 1998 Apr;85(4):457-460.

4. Phillips JL, Weller RN, Kulild JC. The mental foramen: Part1. Size, orientation and positional relationship to the mandibular second premolar. J Endod 1990 May;16(5):221-223.

5. Gershenson A, Nathan H, Luchansky E. Mental foramen and mental nerve changes with age. Acta Anat 1986;126(1):21-28.

6. Dreanna MR. The mental foramen with special reference to its position in the edentulous mandible. S Afr Dent J 1930; 4:494-509.

7. Montague MFA. The direction and position of the mental foramen in the great apes and men. Am J Phys Anthrop 1954; 12(4):503-518.
8. Risenfeld A. Multiple infraorbital, ethmoidal and mental foramina in the races of men. Am J Phys Anthrop 1956;14(1): 85-100.

9. Greeen RM. The position of mental foramen: a comparison between Southern Chinese and other ethnic and racial groups. Oral Surg Oral Med Oral Pathol 1987;63(3):287-290.

10. Philips JL, Weller RN, Kulild JC. The mental foramen part 3. Size and position on panoramic radiographs. J Endo 1992; 18(8):383-386.

11. Philips JL, Weller RN, Kulild JC. The mental foramen; part 2. Radiographic position in relation to the mandibular second premolar. J Endo 1992;18(6):271-274.

12. Kjaer I. Formation and early prenatal location of the human mental foramen. Scan J Dent Res 1989;97(1):1-10.

13. Wang TM, Shih C, Liu JC, Kuo KJ. A clinical and anatomical study of the location of the mental foramen in adult Chinese mandibles. Acta Anat 1986;126(1):29-33.

14. Santini A, Land M. A comparison of the position of the mental foramen in Chinese and British Mandibles.Acta Anatomica, 1990;137(3):208-212.

15. Apinharmit W, Champoong S, Methathrathip D, Sansuk R, Phetphanphiphat W. Supraorbital notch/foramen, infraorbital foramen and mental foramen in Thais: anthrometric measurements and surgical relevance. J Med Assoc Thai 89(5):675-682.

16. Gupta S, Soni J. Study of anatomical variation an incidence of mental foramen in dry mandibles. National J Med Res 2012; 2(1):28-30.

17. Agnihotri S, Patri VM, Sathwane RS. Radiographic determination of position and symmetry of mental foramen in central Indian population. J Indian Academy of Oral Med Radiol 2011;23(2):101-103.

18. Olasoji HO, Tahir A, Ekanem AU, Abubakar AA. Radiographic and anatomic location of the mental foramen in Northern adults. Niger Post Grad Med 2004;11(3):230-233. 